\title{
Estratégia Saúde da Família: avaliando o acesso ao SUS a partir da percepção dos usuários da Unidade de Saúde de Resistência, na região de São Pedro, no município de Vitória (ES)
}

\author{
Family H ealth Strategy: evaluating the access to SUS \\ from the perception of the users of the health unit Resistência, \\ in the region of São Pedro, Vitória, Espírito Santo State
}

Talita Dourado Schwartz ${ }^{1}$

Josilda Terezinha Bertulozo Ferreira²

Ethel Leonor Noia M aciel ${ }^{1}$

Rita de Cássia Duarte Lima ${ }^{1}$

${ }^{1}$ Departamento de Enfermagem, U niversidade Federal do Espírito Santo. Av. M arechal Campos 1.468, Santa Cecília. 29040-090 Vitória ES.

talitaschwartz@gmail.com ${ }^{2}$ Secretaria M unicipal de Saúde deVitória.
Abstract Family H ealth is a re-orientation strategy of the assistance model. One of its guiding principles is the establishment of a link between the health teams and the SU S users. The purpose of this research is to evaluate user access to the Family Health Unit (FHU) and the local problems faced. It is an exploratory, qualitative research, developed at the FHU Resistencia of São Pedro, located in the Greater Vitória, Espírito Santo State, with data collected individually through a semi-structured survey. It was found that the main needs of the population are incorporated in the services provided by theFHU, and the users face many difficulties with access. The main criticism is related to access to the specialized services. The majority of the participants of the survey showed satisfaction with the access to the services, and were not intimidated to express the difficulties faced. The work developed by the Family H eath Strategy (FHS) at FHU Resistência has been contributing to the improvement of the quality of the services offered by FHS to the users served, although many problems have been identified, which demonstrates the great challenge in redefining the assistance model, as proposed by this public policy.

Key words Access, Family Health Strategy, Basic attention, U ser
Resumo A Saúdeda Família éuma estratégia de reorientação do modelo assi stencial. U ma de suas diretrizes éo estabel eci mento de vínculo das equipes de saúde com os usuários do SUS. Este estudo visa avaliar o acesso dos usuários à U nidade Saúdeda Família (USF) eos problemas locais enfrentados. É um estudo exploratório qualitativo, desenvolvido na USF Resistência em São Pedro, Iocalizada no município de Vitória (ES), com dados coletados individualmente, por meio de um questionário semiestruturado. Constata que as principais necessidades da população estão inseridas nas atribuições da USF e que os usuários enfrentam diversas dificuldades de acesso-utilização dos serviços. As principais críticas estão relacionadas às dificuldades de acesso às especialidades. A maioria dos entrevistados mostrou-se satisfeita com 0 acesso ao atendimento e não se intimidou em apontar as dificuldades enfrentadas. 0 trabalho desenvolvido na US Resistência vem contribuindo para a melhoria da qualidade deatendimento aos usuários assistidos pela Estratégia Saúdeda Família. 0 estudo revelou também problemas e dificuldades no acesso, o que mostra, por si só, o grande desafio que é reconstruir um modelo assistencial conforme proposto para a construção dessa política pública.

Palavras-chave Acesso, Estratégia Saúde da Família, Atenção básica, U suário 
Introdução

O Sistema Ú nico de Saúde (SU S) tem representado para a sociedade brasileira um processo civilizatório, forjado no interior dos movimentos sociais contra-hegemônicos na década de setenta. Desde então, a noção de direito e cidadania vem gradativamente se incorporando no interior da sociedade brasileira. Com a aprovação da Constituição Federal de 1988, uma nova base jurídico-legal se instituiu para a política de saúde, estabel ecendo em seu artigo 196 a saúde como direito de todos e dever do Estado.

A saúde como direito impõe ainda ao Estado e à sociedade incorporar a necessidade de ampliação da concepção do processo saúdedoença. Nesse contexto, a lógica que vai nos orientar, enquanto uma sociedade de direito, tem necessariamente que extrapolar e romper com a concepção de saúde como simplesmente ausência de doenças. Nessa perspectiva, a saúde está diretamente relacionada à qualidade de vida, à ideia de bem-estar. Portanto, ao longo desses vinte anos de garantias, limites e avanços constitucionais, a saúde passou a ser compreendida como produção social, ou seja, tem implicações quesão determinadas por complexas redes causais que envolvem elementos sociais, econômicos e culturais que se processam ese sintetizam na experiência concreta de cada sujeito singular, de cada grupo em particular e da sociedade em geral.

A saúde como produção social significa reconhecer que, quanto mais desigual for a distribuição das riquezas, quanto mais precário for o acesso dos grupos sociais aos bens de consumo e a políticas públicas redistribuitivas, mais complexos, heterogêneos einjustos serão os padrões deadoecimento e mortalidade de uma dada sociedade.

Dessa forma, a produção de saúde decorre de dois macrocomponentes que se influenciam mutuamente: (1) a organização de políticas públicas que distribuem renda e (2) a garantia de acesso a serviços e ações integrais de saúde. Ações integrais correspondem, entre outros, à combinação e à articulação entre medidas de promoção e prevenção com as de cura-reabilitação, cuja sinergia deve resultar na oferta aos cidadãos e à sociedade de práticas de saúde resolutivas e de qualidade ${ }^{1}$.

O grau de dificuldade dessa sinergia torna mais remotas as possibilidades de incorporação das lutas pelos direitos de defesa da vida, impedindo que se rompa com a lógica do Estado benfeitor, de favor e de concessões, em particular aos grupos já excluídos dos vários equipamentos públicos, como educação, segurança e saúde, dentre tantos direitos.

Assim, ao se pensar o acesso a políticas públicasno SUS, faz-senecessário identificar o nível de (re)conhecimento dos vários atores que compõem essa sociedade em relação à compreensão e à assimilação dos seus direitos (sociais, civis e políticos), e isso afeta as formas e possibilidades de como a cidadania se enraíza nas práticas sociais.

Já nas sociedades em que estas questões estão com nível de reconhecimento mais elevado do processo civilizatório, o pacto social e federado construído e celebrado intensivamente desdobrase e revela-se no permanente cotidiano da sociedadee do Estado, evitando retrocessos e clamando por aprimoramentos. É o caso de se viver no cotidiano dos serviços os percalços da obtenção dos direitos constitucionais, conforme inscritos pelos princípios e diretrizes do SUS².

N esse sentido, os direitos serão tomados provisoriamente nesse artigo como práticas discursivas e valores que afetam o modo como as desigualdades e diferenças são configuradas no cenário público, como os interesses se expressam e os conflitos se realizam, uma vez que os direitos não dizem respeito apenas às garantias inscritas na lei e nas instituições ${ }^{3}$.

Assim, um dos objetivos do artigo é refletir sobre um dos princípios doutrinários do SUS, que é o direito universalizado de acesso dos usuários aos serviços de saúde. Para esse estudo, tomamos como recorte a real idade do território de São Pedro, localizado no município deVitória(ES).

A garantia de acesso aos serviços de saúde no Brasil está assegurada tomando como referência a aplicação cotidiana dos princípios organizativos e doutrinários do SUS, a partir da corresponsabilidade e da solidariedade dos entes federados, dos gestores, dos trabalhadores e dos usuários.

Nesse processo, vem ganhando destaque 0 poder local representado pelo município, pelas redes e teias de conexões quevão seformando ao organizar os serviços de saúde em suas várias complexidades, notadamente na atenção primaria à saúde (APS), em particular com a Estratégia Saúde da Família (ESF), que traz em sua concepção um redesenho de modelo assistencial que privilegia o vínculo com a lógica de linhas decuidado em que todo cidadão tem o direito de ser cuidado por uma equipe, de forma integral e resolutiva, com projetos terapêuticos cuidadores solidários com as demandas e/ou o sofrimento dos usuários, sendo também produtores de corresponsabilidades e autonomia ou de autogoverno por parte dos envolvidos nesse processo ${ }^{4}$. 
De acordo com Starfield ${ }^{5}$, a APS é o nível de um sistema de serviço de saúde que oferece a entrada e 0 acesso no sistema para as novas necessidades e problemas, fornecendo atenção sobre a pessoa no decorrer do tempo e em todas as condições. Essa autora diferencia os conceitos deacesso e acessibilidade. Afirma que ambos podem ser medidos através do ponto de vista tanto da população quanto da unidade de atenção à saúde.

A constituição cidadã brasileira de 1988 e as leis 8.080 e 8.142 da saúde trouxeram em seu bojo todo o ideário reformador com vista à construção de um Sistema Ú nico de Saúde (SUS), tendo como uma das primícias o acesso universal ao sistema, permitindo que uma nova configuração nos serviços de saúde fosse possível ao priorizar ações de caráter coletivo e preventivo, em detrimento das ações de cunho individual e curativo, até então predominantes ${ }^{6}$.

Para Unglert et al. 7 , 0 acesso engloba inúmeros fatores, que podem ser analisados sob abordagens diversas, que vão do modelo institucional de saúde à prática diária, à satisfação dos usuários, dos trabalhadores de saúde e às questões geográficas. Enfim, a compreensão ea institucionalização são processos complexos, pela diversidade de variáveis.

É nesse sentido que Telles ${ }^{3}$ observa que a obtenção de direitos deve ser vista pelo ângulo da dinâmica societária, uma vez que os direitos dizem respeito, antes demais nada, ao modo como as relações sociais se estruturam e se operacionalizam no dia a dia. Para essa autora, os direitos perpassam por formas de sociabilidade regidas pelo reconhecimento do outro como sujeito de interesses válidos, valores pertinentes e demandas legítimas.

Travassos e $M$ artins $^{8}$, em artigo de revisão sobre os conceitos de acesso, advertem-nos que esseéum conceito complexo, geralmente empregado de forma imprecisa e que muda ao longo do tempo e de acordo com o contexto. M ostram que a utilização dos serviços de saúde representa o centro do funcionamento do sistema e, emboracom divergências conceituais eideológicas, tem predominado a visão de acesso relacionado às características da oferta de serviço, ou seja, o uso de serviços é a sua própria expressão.

Para os fins desse artigo, iremos nos apoiar na compreensão de Travassos e $M$ artins ${ }^{8}$, após a revisão do conceito de acesso, e em vários autores nacionais einternacionais, de que a utilização dos serviços de saúde é resultante da interação do comportamento do indivíduo que procura cuidados edo profissional queo conduz eo acom- panha dentro do sistema de saúde. Travassos e $M$ artins ${ }^{8}$, assim como Cecílio ${ }^{9}$, entendem que 0 uso dos serviços de saúde depen de de fatores predisponentes, das necessidades de saúde e dos fatores contextuais, assim como o uso efetivo e eficiente depende dos fatores individuais e de fatores internos aos serviços de saúde, que interferem na qualidade dos cuidados prestados.

O comportamento do usuário geralmente é que determina o primeiro contato. Ele gera a demanda para o serviço e todos os trabalhadores de saúdeestão implicados nessemomento, independente do lugar técnico/social em que estejam inseridos ${ }^{10}$. A implicação vai desde a pessoa que está na portaria, que pode ser o porteiro ou a atendente, com sua autonomia e poder dado pela "autoridade" para deixar ou não entrar o usuário, até os profissionais de saúde, que vão concretizar os atos de saúde que terão ou não repercussão sobre suas necessidades e motivos que o levaram àquele serviço.

$\mathrm{Na}$ revisão realizada por Travassos e M artins ${ }^{8}$, as autoras identificaram vários autores, inclusive D onabedian, que empregam o substantivo acessibilidade, que seria o caráter ou a qualidade do queéacessível, enquanto outros autores usam o substantivo acesso como ato de ingressar, entrada no serviço.

Para Starfield ${ }^{5}$, os termos acesso e acessibilidade são usados de forma intercalada e ambígua. Ao fazer a distinção entre os dois conceitos, aponta que acessi bilidade é o elemento estrutural necessário para a primeira atenção e depende se o local deatendimento éacessível do ponto de vista da facilidadee da disponibilidade. Caso isso não seja factível, haverá postergação na atenção, podendo, inclusive, comprometer o diagnóstico e o manejo do problema. Existem, assim, vários tipos de acessibilidade.

Citando Donabedian, a autora ${ }^{8}$ afirma que esse autor também faz uma distinção entre acesso socioorganizacional do acesso geográfico. 0 primeiro inclui recursos que facilitam ou dificultam os esforços das pessoas para chegarem ao atendimento, como preconceitos sociais menos explícitos como idade, raça ou classe social, ou alguma forma de pagamento. 0 acesso geográfico, por outro lado, envolve as características relacionadas à distância e ao tempo para alcançar e obter os serviços.

Outra situação verificada por Tavares et al. ${ }^{11}$ se refere ao nível de entendimento e informação da população sobre o que éo SUS e os seus direitos em relação à assistência. A falta de informação se coloca em muitas situações como uma es- 
tratégia de (in)visibilidade sobre os direitos dos usuários e deveres do Estado no papel de gestores etrabal hadores de saúde. Assim, a experiência dos sujeitos com os distintos serviços vai depender de muitas variáveis, tais como as informações que agregam e estão disponíveis a ele, sua percepção sobre as facilidades e dificuldades para a obtenção de cuidados, a compreensão sobre necessidades de saúde que vão se construindo nos processos saúde-doença de usuários e trabal hadores de saúde e, por fim, as formas como irão se estabelecer o vínculo, 0 acolhimento e de como sefarão as rupturas com os processos de desigualdade e exclusão a que muitos usuários têm sido submetidos nos serviços públicos e, nesse caso, no SUS.

Esse alerta é importante ser feito, pois como apontam M agal hães et al. ${ }^{12} \mathrm{em}$ seu estudos sobre desigual dades sociais, ao se incorporarem al guns indicadores, como acesso à educação, a serviços de saúde, à terra e ao saneamento, percebemos a existência de amplos contingentes da população privados de direitos básicos de cidadania, dentre os quais podem-se destacar os grupos dos mais pobres e de baixa escolaridade, os afrodescendentes, os indígenas e os habitantes das regiões Norte e Nordeste, e incluiríamos, também, os bolsões de pobreza no Sul e Sudeste, conforme ocorre no cenário em que a presente pesquisa aconteceu - a região de São Pedro.

Vários autores têm apontado a diminuição das desigual dades e iniquidades no acesso a vários equipamentos sociais. Fleury ${ }^{13}$ ratifica al guns desses achados, mas aponta que, no setor saúde, as iniquidades se referem às diferenças que colocam certos grupos em situação de discriminação e desvantagem no acesso aos serviços, reforçando, assim, as condições de vulnerabilidade da saúde de determinados grupos, uma vez que a oferta deserviços no SUS, apesar dos inegáveis avanços, ainda está muito centrada na oferta da cesta básica de serviços para serem utilizados e acessados pelos pobres e excluídos na nossa população.

Dados da Pesquisa Nacional por Amostra de Domicílios (PNAD) ${ }^{14}$ apontam que, dentre as pessoas que buscaram atendimento de saúde, 25,2 milhões foram atendidas na primeira ou na última procura, perfazendo 98,0\%. M esmo com este alto índice de acesso, a PN AD apontou que ainda existiam no Brasil importantes limitações deacesso aos serviços de saúde. Entretanto, mostrou também que houve, entre 1998 e 2003, meIhora expressiva em vários dos indicadores de acesso analisados.

N esse sentido, como afirma Fleury ${ }^{13}$, é importante que determinadas questões sejam tratadas a partir da sua emergência como "questão social", ou seja, como reconhecimento de novos problemas que emergem na arena política a partir da transformação denecessidades em demandas. I sso só épossível com a constituição de sujeitos da ação, e sua inserção passa necessariamente pelo resgate de suas possibilidades discursivas, de sua autonomia, por estar informado, pela percepção da realidade em que está imerso e pelo reconhecimento dos seus direitos enquanto cidadão no mundo.

0 presente estudo teve como objetivo avaliar a percepção dos usuários sobre as facilidades/dificuldades de acesso en quanto utilização deserviços na ESF, na Unidade de Saúde da Família de Resistência, na Região de Saúde de São Pedro, localizada no município de Vitória, considerando que a Secretaria M unicipal de Saúde de Vitória ${ }^{15}$ coloca que os serviços oferecidos pela US Resistência englobam, principalmente, a consulta mé dica e de enfermagem, atendimento psicológico, social eodontológico, verificação de pressão arterial, curativo, coleta de exames, nebulização, injeção, vacinas, dispensação de medicamentos, grupos de atendimentos a diversos programas e encaminhamentos para os Centros de Referência.

\section{Métodos}

Trata-se de um estudo exploratório, que privilegia a abordagem qualitativa. Os seus resultados representam a realidade provisória, não generalizável e temporal do caso estudado (a Unidade de Saúde da Família de Resistência), apreendendo significados, significações eas percepções, pontos de vista, experiências e as facilidades e dificuldades que os sujeitos relataram ao utilizar os serviços de saúde nessa unidade. U tilizar a abordagem qualitativa nos permitiu, conforme M artins e Bogus $^{16}$ e M inayo ${ }^{17}$, obter respostas muito particulares, uma vez que os sujeitos da pesquisa são singulares, vivenciam uma realidade particular, que é a de ser usuário de um serviço de saúde localizado numa das regiões de periferia mais pobres do município de Vitória, em que as desigualdades no quese refere a grau de escolaridade, renda, segurança, condições de moradia, saneamento e saúde são muito comprometedoras.

A pesquisa foi desenvolvida na Unidade Saúde da Família de Resistência, localizada no bairro São Pedro, um dos bairros criados na periferia da cidade de Vitória na década de setenta em função dos grandes projetos de industrialização no estado, quando houve um acelerado processo de imigração do campo e de outras cidades do país 
em busca de melhores condições de vida, principalmente do acesso ao emprego ou algum tipo de renda. $\mathrm{Na}$ década de noventa, esse bairro foi um dos que sofreram grandes intervenções públicas, com a instalação de serviços de saúde, educação e saneamento, possibilitando ganhos na melhoria das condições de vida e impacto em indicadores como mortalidade infantil.

A escolha do cenário levou em conta a inserção de uma das pesquisadoras como um dos profissionais de saúde que compôs a organização e territorialização da área, com vistas à implantação da primeira Unidade de Saúde na região e do município de Vitória a implementar a Estratégia Saúde da Família.

0 critério de inclusão e participação na pesquisa se deu através da abordagem direta aos usuários, imediatamente após a utilização de algum tipo de serviço no período da coleta dos dados e que, voluntariamente, após todos os esclarecimentos pertinentes, aceitaram responder ao instrumento de pesquisa. Participaram 39 usuários que demandaram algum tipo de serviço nessa unidade, em março de 2007.

Os dados foram coletados na própria unidade de saúde (US), individualmente, por meio de um questionário semiestruturado, contendo vinte perguntas abordando os seguintes aspectos: caracterização do perfil dos entrevistados, utilização dos serviços de saúde, dificuldades de acesso à US, tempo de espera parao atendimento, encaminhamentos e avaliação do atendimento. Para delimitar a suficiência dos dados, utilizou-se o critério de saturação ou ponto de exaustão, quando as respostas foram se repetindo e novas questões não emergiram ${ }^{17}$.

Este estudo obteve aprovação do Comitê de Ética do Centro de Ciências da Saúde da Universidade Federal do Espírito Santo (UFES) e autorização da Secretaria Municipal de Saúde do município de Vitória. Foram assegurados aos participantes o sigilo eo anonimato de suas falas e exposições. Os sujeitos participaram livremente do estudo, tendo sido fornecidas informações necessárias para torná-los conscientes sobre a decisão em participar ou não da pesquisa.

Foram observados todos os procedimentos éticos cabíveis, assim como solicitadas as autorizações necessárias e assinaturas do termo deconsentimento, no qual constavam os objetivos da pesquisa, o seu caráter científico e o compromisso das pesquisadoras de não identificação dos participantes.

Para análise, num primeiro momento foi realizada a organização detodo o material coletado, feita uma leitura flutuante dos dados e, posteriormente, o mesmo foi dividido em partes, em quese procurou identificar tendências, semelhanças e divergências de percepção. D esse trabalho, emergiram as categorias de análise relacionadas ao perfil dos usuários, acesso, percepção sobre a utilização dos serviços, dificuldades efacilidades e avaliação dos serviços. Com base em Bardin ${ }^{18}$, utilizou-se a técnica de análise de conteúdo em que os eixos temáticos foram organizados e reorganizados em confluência com os achados, na tentativa de trazer à cena as semelhanças e os diferentes e às vezes conflitantes pontos de vista, em consonância com o quadro teórico construído e os pontos de vista dos pesquisadores.

\section{Resultados ediscussão}

Das categorias, submergiram quatro subcategorias: perfil da população atendida na US Resistência, utilização do serviço de saúde, tempo de espera para 0 atendimento e avaliação dos usuários quanto ao atendimento da US.

Perfil da população atendida na Unidade de Saúde de Resistência

O perfil dessa população foi majoritariamente de pessoas do sexo feminino, representando $87,2 \%$ dos entrevistados, o que, para Anjos et al. ${ }^{19}$, demonstra uma maior demanda maternoinfantil nas unidades, reafirmando a condição de cuidadora de si e dos familiares como uma questão de gênero. Não se pode deixar de ressaltar que os serviços da ESF estão melhor estruturados para oferecer ações voltadas para a saúde da mulher e da criança, pois, historicamente, a saúde materno-infantil constituiu-se como pauta prioritária no campo da Saúde Pública.

A idade dos usuários entrevistados variou entre 14 e 67 anos, predominando a faixa etária de adulto jovem eadulto (20-29 anos), com onze respondentes e a de 40 a 49 anos, com nove respondentes. Esses dados são favoráveis à obtenção deuma mai or diversidade deopiniões, como defendem Aguiar e M oura ${ }^{20}$, tendo em vista que as demandas, necessidades de saúde e percepções sobre o serviço de saúde variam de acordo com a faixa etária dos indivíduos.

Em relação ao grau de instrução dos entrevistados, um participante era analfabeto, dezenove tinham ensino fundamental incompleto, onze completaram o ensino fundamental, seis tinham ensino médio incompleto, dois comple- 
taram o ensino médio e nenhum dos entrevistados havia iniciado o ensino superior. Foi encontrado predomínio de indivíduos com renda familiar inferior a três salários mínimos.

Esses dados nos permitem pensar, a exemplo de outros estudos, como os de Lima ${ }^{10}$ e Fleury ${ }^{13}$, que o quadro de saúde dos indivíduos, suas características socioeconômicas e os baixos níveis de renda afetam a vida dos indivíduos como um todo, expondo- 0 a contextos deficientes, desgastantes e geradores de doenças, evidenciando as desigualdades no acesso aos serviços de saúde ${ }^{21}$.

Nesse contexto, Aguiar e M oura ${ }^{20}$ ressaltam queaESF tem um papel fundamental, através da articulação com outros setores, como o de educação, para contribuir e aprimorar o acesso à educação (a criação de laços com as famílias e comunidade poderáidentificar, estimular eacompanhar, por exemplo, a frequência escolar), e às estratégias para obtenção de renda, melhorias no saneamento básico eestabelecendo, inclusive, uma relação de intersetorialidade, conforme orientada nas diretrizes da Estratégia.

\section{Utilização do serviço de saúde}

Nesse artigo, se ratificam a complexidade e a diversidade do conceito sobre acesso enquanto utilização dos serviços, que foi entendido como as respostas às demandas que os usuários geraram representadas como serviços: consultas mé dicas, exames, consulta de enfermagem, imunização, dentre outras. Nesse sentido, é importante ressaltar o papel dos profissionais que atuam na ESF, no diálogo e no acol himento a essas demandas da população adscrita, informando, de forma clara e acessível, ao nível de compreensão dos usuários, a respeito da hierarquização dos serviços de saúde explicando o poder de resolução da atenção primária (que resolve em torno de $85 \%$ dos problemas de saúde) e a própria forma de organização e o cardápio de opções que o serviço tem a oferecer. Para isso, os serviços precisam estar organizados e atuar em parceria com cada indivíduo, família e comunidade22. Uma vez que muitos dos serviços procurados pela população de Resistência são de competência da US, há a necessidade de que sejam estabel ecidos mecanismos de organização e informação, facilitando 0 acesso e priorizando casos de risco ou grupos específicos ou vulneráveis que devem ser atendidos por determinados programas ou referenciados a serviços especializados, quando for o caso.

Um dos fatores que levam essa população a buscar outros locais de atendimento não está associado a dificuldades geográficas de localização da unidade, mas sim à dificuldade de acesso, por exemplo, à consulta clínica e ginecológica, por falta deprofissionais em número suficienteà demanda. M uitas são as reclamações quanto aos excessivos encaminhamentos para serviços que a unidade deveria ofertar, tais como consultas de rotina, sendo frequentemente encaminhados para a Policlínica, por falta de profissionais ou por impossibilidade na marcação de consultas, fato que constitui um problema de gestão, com implicações nos direitos dos usuários e nos vínculos que eles estabelecem ou não com o serviço mais geograficamente próximo de onde moram.

Percebemos que muitas das expectativas dos usuários quanto à US estão além do rol de atividades a serem ofertadas na atenção básica, como a solicitação por especialidades, conforme identificado em catorze dos entrevistados, como neurologia, reumatologia, cirurgia, mastologia, oftalmologia, ortopedia, cardiologia, dentreoutros, demonstrando que ainda não está claro para a população o processo de descentralização e hierarquização da rede de serviços, ratificando 0 estudo de Tavares et al. ${ }^{11}$, que identificou na debilidade da referência-contrarreferência ena falta de informação um dos nós críticos na relação do usuário com os serviços no SUS. O esclarecimento quanto à hierarquização do SU S éimportante, para que a própria população possa participar do processo de organização da demanda nos três níveis de atenção, estando uma vez consciente de que a sobrecarga dos níveis secundário eterciário põe em risco a vida daqueles que realmente precisam de atendimento nesses níveis ${ }^{20}$.

Tempo de espera por atendimento

Tempo entre a marcação

e a real ização do atendimento

0 tempo de espera para agendar consultas para acessar a média complexidade se apresentou como um grande dificultador e desafio para organizar as demandas e os serviços.

A maior parte dos usuários relatou a espera por consulta por no máximo um mês. Três entrevistados relataram que as consultas podem demorar mais de dois meses e associam com as especialidades, uma vez que a marcação das especialidadeséfeita naUSF, embora o atendimento não seja realizado no mesmo local, causando confusão no entendimento dessefluxo, se o usuário não for devidamente informado.

Aguardo há dez meses ortopedista.

Especialidades demoram de dois a três meses. 
M arques e Lima ${ }^{23}$ colocam que o que ocorre, muitas vezes, é a burocratização das ações e procedimentos, sen do frequentemente perdida a noção das necessidades da pessoa (cidadão), das potencialidades do sistema e da possibilidade de formação de redes de atendimento. Isso diz respeito também, como afirmam Telles ${ }^{3}$ e Fleury ${ }^{13}$, às formas como as relações sociais são tecidas, tendo a ver, de acordo com Fleury ${ }^{13}$, com as novas institucionalidades produzidas pelas políticas sociais, trazendo para as arenas públicas novos atores, espaços e processos de intermediação de interesses, que tendem a reconfigurar relações de poder, como é o caso dos usuários quando são portadores de informações e de seus direitos.

Referência e contrarreferência

O SUS propõe a hierarquização dos serviços, determinando que funcionem como uma redeintegrada, tendo a redebásica de saúde como porta de entrada preferencial no sistema, de modo que os pacientes só sejam encaminhados à unidade de referência caso o problema não possa ser resolvido naquele nível de complexidade ${ }^{24}$.

Quando perguntados se, caso precisem ser encaminhados, conseguem atendimento e o problema éresolvido em outro local, 36 dos respondentes alegaram que sim, mesmo que colocassem alguma observação, como:

Dependeda especialidade.

Algumas vezes o lugar élonge.

Sim, mas demora.

0 relato negativo veio de três pessoas:

Difícil, nem sempre consegue.

Às vezes, depois da Policlínica, ainda é encaminhado para outro hospital.

Às vezes é atendido, mas demora para solucionar o problema.

Cabe salientar que a grande maioria se referiu ao encaminhamento para a Policlínica de São Pedro, próxima à área da US, em situações que não exigem especialidades, mas sim atendimento ambulatorial, tais como curativos, vacinações epediatria.

Avaliação dos usuários quanto ao atendimento da US

É fundamental conhecer como os usuários avaliam 0 atendimento a eles prestado, para repensar as práticas profissionais ou intervir sobre a forma de organização dos serviços, visando ao seu aperfeiçoamento. É necessário considerar, porém, os limites inerentes a estudos baseados na percepção do usuário22.
Facilidades e dificuldades: a unidade

de saúde e os encaminhamentos

Muitas críticas dos usuáriosse relacionam aos excessivos encaminhamentos, devido à falta de certos recursos na US:

Não é bom, pois nunca podem atender, tudo precisa ser encaminhado para a Policlínica.

Quando atende é bom, o posto é bom, à tarde nunca tem médico, alguns pacientes são encaminhados para a Policlínica.

É importante atentar-se às atribuições da unidade de saúde, organizada para prestar atendimento eletivo a nível ambulatorial eatendimento às intercorrências, recepcionando, acolhendo, registrando e fazendo marcação de consultas, assim como deveria realizar procedimentos de enfermagem e proceder à consulta médica, odontológica e de enfermagem.

A Equipe Saúde da Família

0 trabalho em equipe, embora não seja uma exclusividade da Saúdeda Família, representaum de seus principais pilares, ainda pouco discutido em pesquisas na Saúde Coletiva. A perspectiva da integralidade das ações favorece uma ação interdisciplinar. $\mathrm{Na}$ construção do projeto de Saúde da Família, énecessário que o trabalho em equipe seja norteado por um projeto assistencial comum e que os atores desenvolvam uma ação de interação entre si e com a comunidade ${ }^{25}$.

Araújo e Rocha ${ }^{25}$ recapitulam que, antes da implantação da ESF, na organização do processo de trabalho no interior de cada unidade de saúde, predominava a hegemonia do poder técnico e político dos profissionais médicos, havia conflito com outros profissionais de nível universitário, as categorias denível médio eram mais numerosas, embora menos qualificadas e mais desvalorizadas em termos salariais e técnico-social. Tal contexto histórico levou grande parte da população a obter uma visão do sistema de saúde centrado no profissional médico como o único responsável pela assistência. Essa percepção, apesar dos avanços do SUS/ESF, ainda hoje permeia o imaginário da população, que cotidianamente reivindica como solução dos problemas de acesso e organização dos serviços a consulta médica tradicional eindividual.

Lima $^{10}$, Franco e M erhy ${ }^{4}$ a esse respeito propõem que a organização do processo de trabal ho em saúde tem que mudar o foco de médico/profissional centrado, passando a ser usuário centrado, incorporando-o, inclusive, na dinâmica dos processos protagonizados nos serviços, ou seja, o usuário, ao exercer os seus direitos de acesso uni- 
versal, precisa sair da condição de mero expectador ao que lhe é ofertado pelo serviço/profissionais desaúdecomo projeto terapêutico ao queele - usuário - revela como problema de saúde:

Deveria ser mais organizado, os médicos sempre mudam, não se sabe se vai conseguir médico.

Péssima, falta organização, faltam médicos, someprontuário, não gosto deser consultada aqui, como sou tratada.

Atenciosos, mas às vezes não encontra 0 que necessita, como dentista, clínico geral.

Houve também dificuldade para entender e absorver as atribuições do enfermeiro na ESF:

Regular, quem deveria fazer os preventivos se riam os médicos, e não os enfermeiros.

A implantação da ESF por si só não garantea modificação do modelo assistencial médico-centrado. Essa depende da mudança na forma de se produzir o cuidado, assim como dos diversos modos de agir dos profissionais entre si e com os usuários ${ }^{25}$. Uma das alternativas seria valorizar a atuação de profissionais com uma visão integral do indivíduo e com formação para atuar junto à comunidade, em contraposição ao modelo baseado na especialização do atendimento ${ }^{22}$.

A estrutura física da US também foi citada pelos entrevistados, visto que é uma US muito pequena, com poucas salas e acesso difícil para o segundo andar, devido às escadas:

$\mathrm{N}$ ada a reclamar, é médio, por causa da estrutura, mas os funcionários fazem o que podem.

Ruim, poucas salas de atendimento, muito pe queno para ser uma US.

Acesso ao atendimento

Percebe-se que a demora no atendimento contribui para a diminuição da credibilidade da ESF, dificultando 0 acesso. As afirmações seguintes reforçam essa proposição erevelam que, além dos problemas cotidianos das pessoas, existeuma descrença no serviço de saúde prestado pelo setor público:

Não ébom, porquenem sempretem o que precisa, chega muito cedo eainda não consegue consulta. Só consegue consulta se tiver passando muito mal.

Precisa melhorar, porque sempre precisa ficar esperando.

Ajuda bastante, mas precisa melhorar 0 atendimento, às vezes não consegue marcar.

Foi observado, em alguns casos, certo conformismo em relação à situação na US:

$\mathrm{N}$ ada a reclamar, teveuma época quefoi ruim, mas melhorou.

Não tem outra, vai essa mesmo. Tem muito a melhorar. Dificuldade na marcação, tudo precisa ir para fora. Não tem especialidade. A téjá melhorou bastante, porque já foi pior, sempre são encaminhados, principalmente para a Policlínica.

Entretanto, ao não incorporar a saúde como direito, o usuário acaba tendo uma baixa expectativa quanto ao serviço oferecido à população atendida no SUS, levando muitas vezes ao conformismo, do tipo "nada a reclamar, teve uma época que foi ruim, mas melhorou".

0 medo de reclamar e ser mal compreendido, atendido, tem relação direta com a incorporação dos direitos de que cada indivíduo é ou deveria ser portador num Estado de direitos. Nesse processo, há que se considerar elementos advindos do ol har dos próprios gestores, profissionais, usuários e avaliadores externos ${ }^{20}$.

Alguns depoimentos revelaram o nível desatisfação dos usuários entrevistados como bom, de forma a considerar que a US atende de maneira adequada aos problemas de saúde da população:

Gosto muito.

Agora está bom, mas há dois ou três anos atrás estava uma porcaria.

Quanto aos usuários que afirmaram ausência de dificuldades com relação ao serviço de saúde oferecido, éimportante retornar à análise feita por Aguiar e Moura20, em que mostram que se deve ter cautela antes de se fazer qualquer afirmação generalizada e comprometedora tomando por base, tão somente, as percepções isoladas dos usuários. Ressalta-se que os respondentes constituem um perfil predominantedemulheres de baixa escolaridade e de baixa renda, habitualmente excluídas do acesso a muitos dos equipamentos públicos (educação, saúde, segurança, emprego, lazer, etc.), o que pode nos levar a supor que a proximidade geográfica de um serviço de saúde à sua residência e, em tese, aberto, universal, constitui-se aos olhos dessa população como algo positivo e que não deve ser criticado, sob pena de perda ou restrição da sua entrada nesses serviços.

\section{Consideraçõesfinais}

0 acesso é um elemento essencial para avaliação da qualidade dos serviços de saúde. Propicia a sati sfação do usuário com 0 atendimento, determinando a escolha do serviço e estabelecendo, frequentemente, vínculo ${ }^{26}$, expresso pela ampliação efrequência na utilização dos serviços ofertados ou os que vão se incorporando devido à demanda dos usuários ou por necessidades epidemiológicas que se abrem à produção de novas 
necessidades de saúde, sendo muitas vezes a simples entrada enão a trajetóriano serviço percebida como facilidade pelos usuários.

A avaliação dos usuários quanto à USF Re sistência mostrou-se positiva em vários aspectos, principalmente se comparado a momentos anteriores da implantação da ESF, em que a oferta de serviço de saúde era muito restrita e de baixa qualidade: "antes era uma porcaria, agora melhorou".

0 acesso geográfico nessa pesquisa não seconstituiu em dificuldade, e sim a infraestrutura física da unidade com escada, estreita e área muito pequena, sem conforto para os usuários que irão utilizar os serviços que necessitam, seja para promoção, prevenção ou para restaurar a saúde/a vida.

N esse sentido, deve-se destacar eprestar atenção nas falas referentes aos "excessivos encaminhamentos e à demora para 0 atendimento". É salutar abrir-se à escuta das críticas dos usuários aos modos como os serviços, ainda, estão orga- nizados na ESF na US Resistência, pois como 0 próprio nome prenuncia, resistir pode ser ao mesmo tempo possibilidade para se potencializar, paraser protagonista, reivindicar einfluir em seu próprio destino e produzir autonomia ou autogoverno para perceber o quemelhor lhe convém em várias dimensões e aqui declaradas como o direito qualificado ao acesso aos serviço públicos de saúde, independente da complexidade do serviço. Como apontado por Fleury ${ }^{13}$ e Telles ${ }^{3}$, direitos são garantidos quando se inclui 0 outro como horizonte, como meu semelhante.

Assim, as facilidades e dificuldades apontadas pelos usuários nesse estudo são fruto de um momento quejá passou eque serve de referência para os gestores, profissionais e usuários buscarem formas de recriar o cotidiano do SUS/ESF Resistência, ainda muito afetada por percepções negativas em relação ao acesso, a integralidadee a equidade na organização e na utilização dos serviços ofertados a essa comunidade.

\section{Colaboradores}

TD Schwartz, RCD Lima e JTB Ferreira participaram de todas as etapas da elaboração do artigo; ELN M aciel realizou a análise final ea elaboração da metodologia. 
Referências

1. Pasche DF. Princípios do SUS e a humanização das práticas de saúde. In: Seminário A Humanização do SU S em debate; 2008; Vitória.

2. Santos NR. A reforma do estado 'SUS' e a proposta das fundações públicas ou estatais. Saúde em Debate 2006; 30(72):120-129.

3. Telles VS. Sociedade civil e a construção de espaços públicos. In: Dagnino $E$, organizadores. Os anos 90: Política e sociedade no Brasil. São Paulo: Brasiliense; 1994. p. 91-102.

4. Franco TB, M erhy EE. Programa Saúde da Família: contradições de um programa destinado à mudança do modelo tecnoassistencial. In: M erhy $E E$, Júnior HMM, Josely R, Franco TB, Bueno WS, organizadores. 0 Trabalho em saúde: olhando e experienciando o SU S no cotidiano. São Paulo: H ucitec; 2003. p. 55-124.

5. Starfield B. Atenção primária: equilíbrio entre necessidades de saúde, serviços e tecnologia. Brasília: UNESCO/M inistério da Saúde; 2002.

6. Nascimento MS, Nascimento MAA. Prática da enfermeira no Programa de Saúde da Família: A interface da vigilância da saúde versus as ações programáticas em saúde. Cien Saude Colet 2005; 10(2):333-345.

7. Unglert, $C V S$, Rosenburg $C P$, Junqueira $C B$. Acesso aos serviços de saúde: uma abordagem de geografia em saúde pública. Rev. Saude Publica 1987; 21(5):439-446.

8. Travassos C, M artins M. Uma revisão sobre os conceitos de acesso e utilização de serviços de saúde. Cad Saude Publica 2004: 20(supl.2):190-198.

9. Cecilio LCO. As necessidades de saúde como conceito estruturante na luta pela integralidade e equidade na atenção em saúde. In: Pinheiro $M$, Mattos RA, organizadores. Os sentidos da integralidade na atenção e no cuidado à saúde. Rio de Janeiro: IMS/ UERJ-Abrasco; 2001. p. 113-126.

10. Lima RCD. Enfermeira uma protagonista que produz o cuidado no cotidiano do trabalho em saúde. Vitória: Edufes; 2001.

11. Tavares FL, Laignier MR, Silva MZ, Daros RF, Lima RCD. O SUS que temos e a informação como estratégia de (in) visibilidade. Saude em Debate 2003; 27(65):405-413.

12. M agalhães $R$, Burlandy $L$, Senna MCM . Desigualdades sociais, saúde e bem-estar: oportunidades e problemas no horizonte de políticas transversais. Cien Saude Colet 2007; 12 (6):1415-1421.

13. Fleury S. Pobreza, desigualdades ou exclusão? Cien Saude Colet 2007; 12(6):1422-1428.

14. Instituto Brasileiro de Geografia e Estatística. Pesquisa Nacional por Amostra de Domicílios: Acesso e Utilização de Serviços de Saúde. Rio de Janeiro: IBGE; 2005.
15. Vitória. Secretaria M unicipal de Saúde. Rede M unicipal de Saúde. [site da Internet] [acessado 2008 nov 03] Disponível em: http://www.vitoria.es.gov.br/ secretarias/saude/bmunidades.asp\#resistencia

16. M artins M FN, Bógus CM. Considerações sobre a metodologia qualitativa como recurso para o estudo das ações de humanização em saúde. Saude soc. 2004; 13(3):44-57.

17. M inayo MCS. Pesquisa social: teoria método e criatividade. Petrópolis: Vozes; 1994.

18. Bardin L. Análise de conteúdo. Lisboa: Edições 70; 1979.

19. Anjos LA, Silva DO, Serrão AS, Silva CVC. Vigilância Nutricional em adultos: Experiência de uma Unidade de Saúde atendendo população favelada. Cad Saude Publica 1992; 8(1):50-58.

20. Aguiar ACS, Moura ERF. Percepção do Usuário sobre a atuação da equipe de saúde da família de um distrito de Caucaia-CE. RBPS 2004; 17(4):163-169.

21. Brasil. Secretaria Especial de Políticas para as MuIheres. Retrato das desigualdades de gênero e raça. $3^{\text {a }}$ ed. Brasília: IPEA/U nifem; 2008.

22. Ramos DD, Lima M ADS. Acesso e acolhimento aos usuários em uma unidade de saúde de Porto Alegre, Rio Grande do Sul, Brasil. Cad Saude Publica 2003; 19(1):27-34.

23. Marques GQ, Lima MADS. Demandas de usuários a um serviço de pronto atendimento e seu acolhimento ao sistema de saúde. Rev Latino-am Enfermagem 2007; 15(1):13-19.

24. Araújo $M A L$, Leitão $G C M$. Acesso à consulta a portadores de doenças sexualmente transmissíveis: experiências de homens em uma unidade de saúde de Fortaleza, Ceará, Brasil. Cad Saude Publica 2005; 21(2):396-403.

25. Araujo M B, Rocha PM. Trabalho em equipe: um desafio para a consolidação da estratégia de saúde da família. Cien Saude Colet 2006; 12(2):455-464.

26. Queiroz M VO, Jorge M SB, M arques JF, Cavalcante AM, Moreira KAP. Indicadores de qualidade da assistência ao nascimento baseados na satisfação de puérperas. Texto contexto-enferm. 2007; 16(3):479-487.

Artigo apresentado em 18/01/2008

Aprovado em 10/102008

Versão final apresentada em 12/11/2008 